\title{
Sexual harassment proclivities in men and women
}

\author{
CARL A. BARTLING and RUSSELL EISENMAN \\ McNeese State University, Lake Charles, Louisiana
}

\begin{abstract}
Sexual harassment proclivities in both men and women were studied in 222 college students. They were administered the newly developed Sexual Harassment Proclivities Scale and their scores were compared with a large number of measures, including sex-role stereotyping, adversarial sexual beliefs, sexual conservatism, acceptance of interpersonal violence, rape myth acceptance, likelihood of rape, acceptance of feminism, empathetic concern, sexual activity, and sexual exploitation. Most of the results were statistically significant for both males and females, although correlations tended to be higher for males. A factor analysis of the Sexual Harassment Pruclivities Scale yielded a one-factor solution for both men and women, supporting the view that the scale measures likelihood of sexual harassment.
\end{abstract}

Research needs to be done in several important areas if one is to understand better the concept of sexual harassment. First, surprisingly little has been done to study sexual harassment proclivities other than by looking at reports of victims. What about the tendency of men or women to commit sexual harassment? A study by Pryor (1987) dealt with sexual harassment proclivities in men, but used extreme situations, such as obvious exploitation. Sexual harassment can be more subtle than that. Second, the study of sexual harassment has focused on men as the perpetrators and women as the victims. But, Gutek and Nakamura (1983) found that men and women report equal numbers of social-sexual encounters initiated by the opposite sex in the work site. While not all of these encounters constitute sexual harassment, some may be sexual harassment, or may be considered to be sexual harassment by some. The definition is open to debate, but the Equal Employment Opportunity Commission's (EEOC) is important and is the law:

Unwelcome sexual advance, requests for sexual favors, and other verbal or physical conduct of a sexual nature when submission to such conduct is made either explicitly or implicitly a term or condition of an individual's employment; submission to or rejection of such conduct by an individual is used as the basis of employment decisions affecting the individual; or such conduct has the purpose or effect of unreasonably interfering with an individual's work performance or creating an intimidating, hostile, or offensive work environment. (Equal Employment Opportunity Commission, 1980, p. 74677)

The present study was designed to deal with the issues discussed above, in part by developing the Sexual Harassment Proclivities (SHP) Scale, and by administering it to

Copies of the Sexual Harassment Proclivities Scale or requests for reprints should be sent to either C. A. Bartling or R. Eisenman, Department of Psychology, McNeese State University, Lake Charles, LA 70609-1895. women as well as to men. It is important to look at both genders as possible perpetrators of sexual harassment, and not to confine the definition or examples to men only. Men may be victims of sexual harassment, but males may be less likely to report it, or may not perceive it as sexual harassment. Thus, we need to know whether women as well as men have proclivities to sexually harass, and what the correlates of such proclivities for both sexes are.

We studied several measures in relation to the SHP Scale. On the basis of previous research (Burt, 1980; Davis, 1980; Eisenman, 1991, in press; Gutek, 1982; Malamuth, 1981; Prendergast, 1991; Pryor, 1987; Smith, Ferree, \& Miller, 1975), we chose, among others, the following measures to study the correlates of sexual harassment proclivities: sex-role stereotyping, adversarial sexual beliefs, sexual conservatism, acceptance of interpersonal violence, rape myth acceptance, likelihood of rape, acceptance of feminism, empathetic concern, sexual activity, and sexual exploitation. These seem to be characteristics that might be related to sexual harassment, although their relationship to sexual harassment seems more obvious for men than for women. Would women who score high on some of these measures also score high on the SHP Scale?

The 30-item questionnaire, based on research findings and theories of sexual harassment, was constructed by the senior author. Respondents indicated their extent of agreement or disagreement with each item on a scale from 1 (strongly disagree) to 5 (strongly agree). Statements were constructed to reflect the EEOC (1980) definition that sexual harassment consists of unwanted sexual attention (e.g., "Women are flattered by sexual advances from men even when they fail to respond positively to these sexual advances"').

Sexual harassment as a product of sex-role spillover (Gutek \& Morasch, 1982) was reflected in several statements (e.g., "Women should be treated differently than men, even at work"). Related to the sex-role spillover hy- 
pothesis is the idea that sexual harassment behaviors are the result of communication problems between men and women (Cohen, 1983). Several questionnaire items reflected this idea (e.g., "'Women often mean 'maybe' or even 'yes' when they say 'no' to sexual advances by men').

Other items included those to assess people's views of the appropriateness of sexual jokes or touching at work. Some items were written to assess respondents' beliefs. Others were written to reflect behavioral tendencies of respondents (e.g., "If I were a supervisor on a job, I would not hesitate to ask an attractive subordinate for a date'). A small pilot study was conducted with 13 male and 29 female participants completing the 30-item SHP questionnaire in small, mixed-gender groups. The 10 most reliable items from this pilot study were then selected to form the SHP Scale. Item-total correlations for this 10item scale ranged from .50 to .85 .

The pilot study was followed by a more extensive study to examine the reliability of the SHP Scale along with the discriminant and convergent validities of the scale with other measures. Data were collected within classroom settings and through a representative mail survey. These two methods were used to assess the importance of the context of completing surveys dealing with sexual attitudes.

\section{METHOD}

\section{Subjects}

There were 60 male and 162 female undergraduate students who completed the SHP Scale and accompanying measures. Of these, 27 men and 68 women completed the surveys within the context of classroom settings in small (5-15), mixed-gender groups. The remaining 33 men and 94 women received and returned the surveys through the mail. In both cases, the responses were completely anonymous. The participants came from a small liberal arts college in Arkansas and from a regional state university in Florida.

\section{Procedure}

The participants completed the SHP Scale and a series of other measures. The first four listed below are the same as those used in Pryor's (1987) Study 1.

1. Burt's (1980) Six Attitude/Belief Scales, including the following: (1) own sex-role satisfaction, (2) sex-role stereotyping, (3) adversarial sexual beliefs, (4) sexual conservatism, (5) acceptance of interpersonal violence, and (6) rape myth acceptance.

2. FEM Scale (Smith et al., 1975).

3. Likelihood of Rape (LR) Index (Malamuth, 1981).

4. Interpersonal Reactivity Inventory (IRI) (Davis, 1980, 1983). This inventory measures four dimensions of empathy: (1) fantasy, (2) perspective taking, (3) empathetic concern, and (4) reactions to persons in distress.

5. A Sexual Activity (SA) Scale, developed by the authors of the present study, had participants indicate the number of times (from none to four or more) that they had given various forms of sexual attention to someone at work during the past 2 years. These included: (1) sexual favors or requests for sexual favors, (2) sexual touching, leaning over, cornering, or pinching, (3) sexually suggestive looks or gestures, (4) letters, phone calls, or materials of a sexual nature, (5) requests for dates or actual dating, and (6) sexual teasing, jokes, remarks, or questions of a sexual nature.

6. On a Sexual Exploitation Index (SEI), respondents rated from 1 (strongly disagree) to 5 (strongly agree) their extent of agreement with the following statement: "If I could get away with it, I would use a supervisory position at work to advance a sexual interest of mine with a subordinate." The SEI is an abstracted version of Pryor's (1987) Likelihood to Sexually Harass (LSH) Scale without the series of 10 scenarios and specific roles (e.g., professor/student) used by Pryor.

\section{RESULTS}

\section{Testing Context}

There was only one variable (LR) that showed a statistically significant difference across context of survey administration, and only for men. There was zero variability on the LR Index for men who completed the survey within a mixed-gender, classroom setting. All 27 male students reported that it was "not at all likely" that they would rape even if they could be assured of not being caught and punished. For the 33 male students completing the mail survey, 10 responded with higher likelihood responses (2-5) on the LR Index, ranging from fairly unlikely to very likely.

\section{Institutional Setting}

There were no statistically significant differences for any of the variables across the two institutions sampled. Because of the relatively small sample sizes, the data sets were collapsed across the two institutions and across the two survey contexts for subsequent analyses.

\section{Reliability}

Coefficient alphas were .86 for men and .74 for women.

\section{Factor Analyses}

Table 1 shows eigenvalues for three kinds of factor analyses: principal components, varimax rotation, and oblique rotation. A principal components factor analysis suggested one primary factor and possibly two secondary factors for the SHP Scale. These three factors accounted for $65 \%$ of the variance for the men and $51 \%$ of the variance for the women. When an oblique rotation was used, only one primary factor was evident. Table 2 shows the item-total correlations and principal components analysis for the SHP Scale.

\section{Correlations With Other Scales}

Table 3 provides the correlations of the SHP Scale with the other measures in this study. Of the six Burt (1980) subscales, the one that yielded the highest correlation to SHP for men and women was adversarial sexual beliefs (e.g., " A lot of women seem to get pleasure in putting

Table 1

Eigenvalues for Factor Analyses for the Sexual Harassment Proclivity Scale

\begin{tabular}{lccc}
\hline \multirow{2}{*}{$\begin{array}{c}\text { Type of } \\
\text { Factor Analysis }\end{array}$} & \multicolumn{3}{c}{ Factor } \\
\cline { 2 - 4 } & Men & 2 & 3 \\
\hline Principal components & 4.43 & 1.10 & 1.02 \\
Varimax rotation & 2.84 & 1.81 & 1.90 \\
Oblique rotation & 4.00 & 0.88 & 0.70 \\
& Women & & \\
Principal components & 2.97 & 1.16 & 1.00 \\
Varimax rotation & 1.91 & 1.69 & 1.53 \\
Oblique rotation & 2.78 & 0.69 & 0.56 \\
\hline
\end{tabular}


Table 2

Item-Total Correlations and Principal Components Analysis for the SHP Scale

\begin{tabular}{|c|c|c|c|c|c|c|c|c|c|c|}
\hline \multirow{3}{*}{$\begin{array}{l}\text { Scale } \\
\text { Item }\end{array}$} & \multicolumn{5}{|c|}{ Men } & \multicolumn{5}{|c|}{ Women } \\
\hline & \multirow{2}{*}{$\begin{array}{c}\text { Item-Total } \\
\text { Correlations }\end{array}$} & \multicolumn{4}{|c|}{ Factor Loadings } & \multirow{2}{*}{$\begin{array}{c}\text { Item-Total } \\
\text { Correlations }\end{array}$} & \multicolumn{4}{|c|}{ Factor Loadings } \\
\hline & & F-1 & F-2 & F-3 & Comm. & & F-1 & F-2 & F-3 & Comm. \\
\hline 1 & .66 & .69 & -.23 & -.53 & .80 & .62 & .65 & -.29 & -.38 & .65 \\
\hline 2 & .70 & .69 & -.10 & .13 & .51 & .58 & .57 & -.22 & .24 & .43 \\
\hline 3 & .57 & .54 & -.59 & .40 & .81 & .55 & .53 & .58 & .19 & .66 \\
\hline 4 & .74 & .75 & -.19 & -.01 & .60 & .55 & .58 & .20 & .23 & .43 \\
\hline 5 & .56 & .52 & .37 & .59 & .76 & .43 & .37 & -.42 & .45 & .52 \\
\hline 6 & .66 & .65 & .01 & .30 & .51 & .48 & .48 & .62 & -.12 & .63 \\
\hline 7 & .72 & .74 & .28 & -.25 & .69 & .44 & .40 & -.17 & .45 & .39 \\
\hline 8 & .53 & .52 & .62 & -.05 & .67 & .43 & .43 & -.01 & .06 & .19 \\
\hline 9 & .72 & .72 & .11 & -.15 & .56 & .49 & .54 & -.21 & -.46 & .55 \\
\hline 10 & .75 & .77 & -.15 & -.16 & .64 & .71 & .77 & -.10 & -.25 & .67 \\
\hline \multicolumn{2}{|c|}{ Eigenvalues } & 4.43 & 1.10 & 1.02 & 6.54 & & 2.97 & 1.16 & 1.00 & 5.12 \\
\hline
\end{tabular}

men down"). Pryor (1987) found a similar result with his LSH Scale.

Malamuth's (1981) LR Index yielded a statistically significant correlation $(r=.35)$ with the SHP Scale for men, but only a modest correlation $(r=.16)$ for women. As one would expect, almost all of the women in the study endorsed "not at all likely" as their likelihood to rape.

The second highest correlation $(r=.64)$ for men (highest for women, $r=.56$ ) was between the SHP Scale and the FEM Scale. Individuals low on a sexual harassment scale would be expected to have stronger feminist attitudes and vice versa (Pryor, 1987). (Higher FEM scores correspond to fewer or weaker feminist attitudes.) The strong relationship between scores on the SHP Scale and scores on the FEM Scale provides further evidence for the construct validity of the SHP Scale.

Scores on the SHP Scale were negatively correlated with the perspective taking and empathetic concern subscales of the IRI (Davis, 1980) for men $(r=-.54)$ and for

Table 3

Correlations of the SHP Scale with Other Measures

\begin{tabular}{lcc}
\hline & \multicolumn{2}{c}{ Pearson $r$ s } \\
\cline { 2 - 3 } \multicolumn{1}{c}{ Measure } & Men & Women \\
& $n=60$ & $n=162$ \\
\hline Age & -.17 & -.11 \\
Burt (1980) scales & -.11 & $-.21 \dagger$ \\
Own sex-role satisfaction & $.55 \dagger$ & $.29 \dagger$ \\
Sex-role stereotyping & $.73 \dagger$ & $.50 \dagger$ \\
Adversarial sexual beliefs & $.49 \dagger$ & $.36 \dagger$ \\
Sexual conservatism & $.54 \dagger$ & $.42 \dagger$ \\
Acceptance of interpersonal violence & $.49 \dagger$ & $.42 \dagger$ \\
Rape myth acceptance & & \\
Malamuth (1981) index & $.35 \dagger$ & $.16 *$ \\
Likelihood of rape & & \\
Smith, Ferree, and Miller (1975) & $.64 \dagger$ & $.56 \dagger$ \\
scale: FEM & & \\
Davis (1980) scales & -.06 & $-.14 *$ \\
Fantasy & $-.36 \dagger$ & $-.16 *$ \\
Perspective taking & $-.54 \dagger$ & $-.20 \dagger$ \\
Empathetic concern & .15 & .09 \\
Reactions to personal distress & $.44 \dagger$ & $.20 \dagger$ \\
Sexual Activity Scale & $.54 \dagger$ & $.31 \dagger$ \\
Sexual Exploitation Index & & \\
\hline${ }^{*} p<.05 . \quad+p<.01$. &
\end{tabular}

women $(r=-.20)$. Pryor (1987) suggested that such findings may be important in understanding the personality characteristics of sexual harassers. For example, as the results from the current study indicate, sexual harassers may find it difficult to empathize with their victims.

Finally, the SHP Scale was significantly correlated with both male $(r=.44)$ and female $(r=.20)$ respondents' reports of their sexual activity at work over the past 2 years and with their likelihood of sexually exploiting subordinates ( $r s=.54$ and .31 for men and women, respectively).

In general, the correlations between the SHP Scale and the other measures were higher for men than they were for women. However, the correlation patterns are strikingly similar for men and women. Also, the correlations between the SHP Scale and the other measures were consistently higher than those obtained for the LSH Scale in Pryor's (1987) study, except for the correlations with Malamuth's (1981) LR Index. Again, it should be noted that Pryor chose to measure an extreme form of sexual harassment proclivity (i.e., sexual exploitation), which is closer to the measure of likelihood of rape.

\section{Regression Analyses}

Stepwise multiple regression analyses were performed to assess the redundancy in these relationships. The score on the SHP Scale was considered as the dependent variable. Four variables entered the regression equation for men: (1) adversarial sexual beliefs, (2) FEM, (3) LR, and (4) SEI. The multiple $r$ was .83, $p<.01$. Four variables entered the regression equation for women: (1) adversarial sexual beliefs, (2) FEM, (3) SEI, and (4) rape myth acceptance. The multiple $r$ was $.72, p<.01$.

\section{Gender Comparisons}

Table 3 shows correlations of the SHP Scale with other measures, while Table 4 provides the means, standard deviations, and $t$ value comparisons for the variables measured in this study for male and female respondents.

Responses made by men were clearly different from responses made by women for four of the measures in this study: (1) acceptance of interpersonal violence (men being more accepting), (2) FEM (women being more 
Table 4

Variable Means, Standard Deviations, and $t$ Values

\begin{tabular}{|c|c|c|c|c|c|}
\hline \multirow[b]{2}{*}{ Measure } & \multicolumn{2}{|c|}{ Men $(n=60)$} & \multicolumn{2}{|c|}{ Women $(n=162)$} & \multirow[b]{2}{*}{$t$} \\
\hline & $M$ & $S D$ & $M$ & $S D$ & \\
\hline Age & 26.05 & 9.74 & 24.61 & 7.86 & 1.13 \\
\hline \multicolumn{6}{|l|}{ Burt (1980) scales } \\
\hline Own sex-role satisfaction & 50.25 & 11.04 & 50.81 & 9.32 & -0.37 \\
\hline Sex-role stereotyping & 33.19 & 7.50 & 31.21 & 6.53 & $1.91^{*}$ \\
\hline Adversarial sexual beliefs & 25.75 & 10.48 & 23.79 & 8.02 & 1.47 \\
\hline Sexual conservatism & 38.44 & 7.03 & 38.06 & 6.54 & 0.38 \\
\hline Acceptance of interpersonal violence & 13.14 & 4.66 & 10.74 & 4.33 & $3.56^{*}$ \\
\hline Rape myth acceptance & 52.78 & 11.37 & 49.83 & 10.20 & $1.84^{*}$ \\
\hline Malamuth (1981) index likelihood of rape & 1.41 & 0.84 & 1.04 & 0.33 & $3.52 \dagger$ \\
\hline Smith, Ferree, and Miller (1975) scale: FEM & 50.34 & 12.41 & 42.69 & 10.03 & $4.69 \dagger$ \\
\hline \multicolumn{6}{|l|}{ Davis (1980) scales } \\
\hline Fantasy & 14.39 & 4.56 & 16.48 & 6.25 & $-2.34 \dagger$ \\
\hline Perspective taking & 18.25 & 4.67 & 17.96 & 4.68 & 0.41 \\
\hline Empathetic concern & 19.66 & 4.42 & 22.11 & 4.30 & $-3.72 \dagger$ \\
\hline Reactions to personal distress & 9.47 & 4.88 & 11.25 & 5.23 & $-2.27 *$ \\
\hline Sexual Activity Scale & 4.34 & 2.61 & 2.67 & 1.16 & $2.23 *$ \\
\hline Sexual Exploitation Index & 1.71 & 0.95 & 1.42 & 0.68 & $2.54 \dagger$ \\
\hline Sexual Harassment Proclivity Scale & 26.63 & 7.42 & 24.83 & 5.92 & $1.86^{*}$ \\
\hline
\end{tabular}

${ }^{*} p<.05$ (one-tailed test). $\quad \dagger p<.01$ (one-tailed test)

profeminist), (3) empathetic concern (women showing more empathetic concern), and (4) LR (men responding with higher likelihoods to rape).

Other differences shown in Table 4 are generally dependent upon using one-tailed $t$ tests and not correcting alpha for multiple tests. For example, average scores for men were only marginally higher than average scores for women on the SHP Scale (26.63 vs. 24.83$)$.

\section{DISCUSSION}

The current study demonstrated reliability, discriminant validity, and convergent validity for the SHP Scale. Correlations with related measures were generally higher for the SHP Scale than for Pryor's (1987) LHS Scale.

The reliability estimates and factorial validity of the SHP Scale were generally weaker for female respondents. However, the SHP Scale did show statistically significant correlations with the women's responses on the SA Scale and the SEI (all $p s<.01$ ). Also, multiple regression analyses for the SHP Scale were similar for men and women, with adversarial sexual beliefs, the FEM Scale, and the SEI emerging as important variables for both men and women. Likelihood to rape entered the regression equation for men, and rape myth acceptance was the fourth variable entering the regression equation predicting SHP scores for women.

The personality profiles for those likely to initiate sexually harassing behaviors appear to be similar for men and women. Adversarial sexual beliefs and weak empathy skills may predispose both men and women to initiate sexually harassing behaviors, including sexual exploitation (cf. Pryor, 1987). It would seem intuitively correct, however, that women would feel more threatened by unwanted sexual attention and be more likely to construe such episodes as sexual harassment.

\section{REFERENCES}

BURT, M. (1980). Cultural myths and supports for rape. Journal of Personality \& Social Psychology, 38, 217-230.
CoHEN, L. R. (1983). Nonverbal (mis)communication between managerial men and women. Business Horizons, 26, 13-17.

DAvis, M. H. (1980). A multidimensional approach to individual differences in empathy. JSAS Catalog of Selected Documents in Psychology, 10, 85.

DAvis, M. H. (1983). Measuring individual differences in empathy: Evidence for a multidimensional approach. Journal of Personality \& Social Psychology, 44, 113-126.

Eisenman, R. (1991). From crime to creativity: Psychological and social factors in deviance. Dubuque, IA: Kendall/Hunt.

Eisenman, R. (1993). Professor Anita Hill versus Judge Clarence Thomas: The view of students at a Southern university. Bulletin of the Psychonomic Society, 31, 179-180.

EQUAL EMPloyment OPPORTUNITY CoMmission. (1980). Interpretative guidelines on sexual harassment. Federal Register, 45, 74677.

GUTEK, B. A. (1982). A psychological examination of sexual harassment. Institute of Industrial Relations, 32, 131-163.

GuteK, B. A., \& MoRASCH, B. (1982). Sex-ratios, sex role spillover, and sexual harassment of women at work. Journal of Social Issues, 38, 55-74.

Gutek, B. A., \& Nakamura, C. Y. (1983). Gender roles and sexuality in the world of work. In E. R. Allgeier \& N. B. McCormick (Eds.), Changing boundaries: Gender roles and sexual behavior (pp. 182201). Palo Alto, CA: Mayfield.

Malamuth, N. M. (1981). Rape proclivity among males. Journal of Social Issues, 37, 138-157.

PRENDERGaST, W. E. (1991). Treating sex offenders in correctional institutions and outpatient clinics: A guide to clinical practice. New York: Haworth.

Pryor, J. B. (1987). Sexual harassment proclivities in men. Sex Roles, 17(5/6), 269-290.

Smith, E., Ferree, M., \& Miller, F. (1975). A short scale of attitudes toward feminism. Representative Research in Social Psychology, 6, 51-56. 